\title{
Do Body Mass Index Levels Correlate with Tinnitus Among Teachers?
}

\author{
Luciana Lozza de Moraes Marchiori ${ }^{10}$ Glória de Moraes Marchiori ${ }^{1,2}$ Priscila Carlos ${ }^{1,2}$ (1) \\ Samuel Lopes Benites ${ }^{1,3(0)}$ Marina Stephany Bobroff Mendes ${ }^{4(0)}$ Daiane Soares de Almeida Ciquinato ${ }^{4,5}$
}

${ }^{1}$ Interdisciplinary Health Promotion Intervention Laboratory, Universidade Cesumar, Maringá, PR, Brazil

${ }^{2}$ Scholarship Undergraduate Research, Universidade Cesumar, Maringá, PR, Brazil

3 Postgraduation Program in Health Sciences, Universidade Estadual de Maringá, Maringá, PR, Brazil

${ }^{4}$ Doctoral and Master's programs in Rehabilitation Sciences, Universidade Estadual de Londrina/ Universidade Pitágoras Unopar, Londrina, Paraná, Brazil

5 Departament of Occupational Health, Prefecture of Cambe, Cambe, PR, Brazil
Address for correspondence Luciana Lozza de Moraes Marchiori, PhD, Interdisciplinary Health Promotion Intervention Laboratory (LIIPS), Cesumar University, 1610 Guedner Av, Aclimação, Maringá, PR, Brazil (e-mail: luciana.marchiori@unicesumar.edu.br).

Int Arch Otorhinolaryngol 2022;26(1):e63-e68.

\begin{abstract}
Keywords

- body mass index

- levels

- correlate

- teachers

- tinnitus

Introduction Working conditions can contribute to the development of lifestylerelated diseases among teachers, including obesity and tinnitus. Describing tinnitus in relation to characteristics and comorbidities can help the treatment and prognosis of teachers affected by this symptom.

Objective To verify a possible association between tinnitus complaint and body mass index (BMI) in teachers.

Methods Cross-sectional study with a sample of teachers who responded to the Visual Analog Scale (VAS) and to the Tinnitus Handicap Inventory (THI). The BMI $(\mathrm{kg} / \mathrm{m} 2)$ was calculated based on self-reported body weight (in kilograms) divided by height (in meters squared). Nonparametric statistics were applied adopting a significance level $<0.05$

Results A total of 83 teachers were assessed, with a mean age $48 \pm 9.7$ years old; $63.9 \%(n=53)$ were females; $44.6 \%$ were eutrophic $(n=37)$, and $16.9 \%(n=14)$ were obese. Of the total, $19.3 \%(n=16)$ reported tinnitus. No differences were found between the groups and BMI $(p>0.05)$, although there was a significant difference between the Tinnitus and No Tinnitus groups for age $(p<0.001)$. The chi-squared test showed an association between age group and tinnitus $(p<0.028)$; those with tinnitus were in the 49 to 65 years old age group. In addition, there was a moderate correlation between tinnitus parameters (VAS; THI-Functional; THI-Total) and BMI.

Conclusion There was a moderate correlation between tinnitus parameters and BMI indicating that, as the BMI increased, so did the impact of tinnitus in the lives of the teachers. Body mass index should be considered a factor in tinnitus assessment and rehabilitation process.
\end{abstract}

received

September 5, 2020

accepted

November 9, 2020

published online

June 28, 2021
DOI https://doi.org/

10.1055/s-0040-1722251. ISSN 1809-9777. (c) 2021. Fundação Otorrinolaringologia. All rights reserved.

This is an open access article published by Thieme under the terms of the Creative Commons Attribution-NonDerivative-NonCommercial-License, permitting copying and reproduction so long as the original work is given appropriate credit. Contents may not be used for commercial purposes, or adapted, remixed, transformed or built upon. (https://creativecommons.org/ licenses/by-nc-nd/4.0/)

Thieme Revinter Publicações Ltda., Rua do Matoso 170, Rio de Janeiro, RJ, CEP 20270-135, Brazil 


\section{Introduction}

The working conditions of teachers can contribute to their developing lifestyle-related diseases, including obesity and tinnitus. Tinnitus is a common symptom with a potentially negative impact on quality of life. More research is required to obtain a deeper understanding of the disease and its clinical presentation. The description of tinnitus-related characteristics in these patients (such as lifestyle) and comorbidities (such as overweight) and the estimate of the incidence of tinnitus can help the treatment and prognosis of patients affected by this symptom. ${ }^{1,2}$

Tinnitus is defined as a sound a person hears that is generated by the body, rather than by an outside source. Most tinnitus is subjective. This means the examiner cannot hear it, and there are no tools to measure or hear that sound. ${ }^{3}$ Tinnitus is the perception of sound in the absence of any external stimulus. Symptoms can be unilateral or bilateral, present with or without hearing loss, and resemble ringing, hissing, whistling, humming, buzzing, chirping, or clicking sounds. Tinnitus can be categorized qualitatively as nonpulsatile (typically subjective) or pulsatile (often objective). Subjective nonpulsatile tinnitus is the most common and is only heard by the patient, whereas objective pulsatile tinnitus can sometimes be heard by an observer and is caused by an internal bodily vibration or noise. ${ }^{4}$ However, poor habits, such as lack of regular physical activity, low level of physical fitness, few hours of sleep, and nutritional disorders are risk factors for several metabolic and circulatory changes that cause various symptoms, such as hearing loss, tinnitus, and dizziness. ${ }^{5,6}$

Anthropometric factors, including body mass index (BMI), may influence tinnitus, although this is still a controversial issue in the literature. ${ }^{1,2,7}$ Data collected from a crosssectional study, which aimed to characterize tinnitus in middle-aged and older outpatients attending a specialized clinic in a developing country, demonstrate that 79 patients had complaints of tinnitus - a crude prevalence of $14.5 \%$, which increased steadily along with the age groups. Of the patients, $51.9 \%$ experienced tinnitus for a short period; $53.2 \%$ reported symptoms in only one ear; and $54.4 \%$ had discrete tinnitus, as opposed to multiple types of it. Intermittent symptoms were experienced by $75.9 \%$ of the patients; $70.9 \%$ were nonpulsatile. Tinnitus was significantly associated with abnormal audiometric patterns, an overall increase in hearing thresholds, high-tone hearing loss, vertigo, hypertension, and obesity ${ }^{8}$-that is, BMI is an anthropometric factor that can influence tinnitus symptoms.

A high BMI with a prevalence of overweight/obesity is a trend observed in different populations, including teachers. A cross-sectional study aimed to assess the prevalence of overweight/obesity and the sociodemographic, occupation$\mathrm{al}$, and lifestyle factors associated with it in public teachers. The sample consisted of 300 teachers, and the conclusion was that the prevalence was significantly higher among male teachers (58.2\%). After multivariate analysis, only gender (95\% confidence interval $[\mathrm{CI}]=0.16-0.66)$ and consumption of fruits and vegetables $(95 \% \mathrm{CI}=0.25-0.98)$ remained significantly associated with overweight/obesity among teach- ers. These findings call for a debate on the need for encouraging an active lifestyle on the part of the teachers. ${ }^{9}$ Few studies have examined anthropometric factors in patients with tinnitus, not to mention the few studies on BMI and tinnitus effects of teachers. Therefore, the present study aimed to verify a possible association between tinnitus complaint and BMI in teachers and to describe characteristics of the patients (such as lifestyle factors and comorbidities), in order to help the treatment and prognosis of those affected by this symptom.

\section{Methods}

The present cross-sectional study was conducted in partnership with the State University of Londrina/Pitagoras UNOPAR University. It is part of broader research named PRÓ-MESTRE Health, Lifestyle and Work of Schoolteachers of the Public System of Londrina. ${ }^{7}$ The project was approved by the Human Research Ethics Committee; all the patients were previously informed about its purpose and procedures and signed the Informed Consent Term. The inclusion criteria encompassed being middle- and high-school teachers, who were actively teaching, who were in charge of a subject in class, who had been in the profession for $>12$ months and who had not had a leave of absence for $>30$ days in the previous 12 months. The exclusion criteria encompassed not being able to answer the audiological evaluation or the Tinnitus Handicap Inventory (THI) questionnaire. The statistical power of the sample was calculated based on a post-hoc test by Portney $2020,{ }^{10}$ with GPower 3.1.7 software (Heinrich-Heine-Universität, Düsseldorf, Northrhine-Westphalia, Germany), using the correlation obtained between the BMI and the Visual Analogue Scale (VAS) for tinnitus. It demonstrated $r_{s}=0.6, \alpha=0.05, n=16, \rho=0$ under $\mathrm{H}_{0}$ with the power of $73 \%$

The lifestyle characteristics were assessed with a questionnaire, answered either personally or with trained interviewers. The clinical information of the patients to carry out the research was collected with routine audiological assessment, based on Miller's history protocol; it included questions about age, gender, and tinnitus. ${ }^{10}$ There were specific questions for tinnitus, investigating whether the sensation of tinnitus was present, in which ear, how often, when the symptom began, and what type of tinnitus the participant has presented as chief complaint. ${ }^{11}$ The Brazilian version of the THI was administered to those who reported tinnitus, ${ }^{12}$ as well as the VAS, in order to assess the level of annoyance caused by tinnitus. ${ }^{13}$ The BMI $\left(\mathrm{kg} / \mathrm{m}^{2}\right)$ was calculated based on self-reported body weight (in kilograms) divided by height (in meters squared).$^{14}$ They were classified as follows: <18.5: underweight; 18.5 to 24.99: normal, or eutrophic; 25.0 to 29.99: overweight; and $\geq 30.0$ : obese. The BMI calculation and classification followed the National Center for Chronic Disease Prevention. ${ }^{15}$

IBM SPSS Statistics for Windows, Version 20.0 (IBM Corp. Armonk, NY, USA) was used for the statistical data analysis, with a $95 \% \mathrm{CI}$ and a significance level of $5 \%(p<0.05)$ established for all tests used. The parametric distribution of the data was verified through the Shapiro-Wilk test; without the 
assumption of normality, the Mann-Whitney test was used for continuous variables. The Spearman correlation test was performed to analyze the correlation between the BMI variables and tinnitus parameters. The Spearman correlations were classified as weak (when the correlation was $<0.4$ ) or moderate (between 0.4 and 0.5 ). ${ }^{10}$ The chi-squared test was performed to analyze the association with categorical variables.

\section{Results}

A total of 83 teachers were assessed, with a mean age $48 \pm 9.7$ years old; $63.9 \%(n=53)$ were females, $36.1 \%(n=30)$ were males, $44.6 \%$ were eutrophic $(n=37)$ and $16.9 \%(n=14)$ were obese. Of the total, $19.3 \%(n=16)$ reported tinnitus. The median for the THI-Total was 18, and for VAS-tinnitus, 4. The descriptive data of the sample are shown in - Table 1.

No difference was found between the groups and BMI (Mann-Whitney test; $\mathrm{p}>0.05$; - Table 2); however, there

Table 1 Descriptive data of the sample $(n=83)$

\begin{tabular}{|l|l|}
\hline General Characteristics & \\
\hline Gender & \\
\hline Female & $n=53(63.9 \%)$ \\
\hline Male & $n=30(36.1 \%)$ \\
\hline Age range (years old) & \\
\hline $27-48$ years old & $n=45(54.2 \%)$ \\
\hline $49-65$ years old & $n=38(45.8 \%)$ \\
\hline Mean \pm standard deviation & $48 \pm 9.7$ \\
\hline Weekly workload & $30[40]^{\mathrm{a}}$ \\
\hline Weight (Kg) & $72[22]$ \\
\hline Height (m) & $1.65[0.7]$ \\
\hline BMI & $26.1[5.4]$ \\
\hline BMI (classification) & \\
\hline Low weight $(<18.50)$ & $n=0(0.0 \%)$ \\
\hline Eutrophic (18.50 at 24.99) & $n=37(44.6 \%)$ \\
\hline Overweight (25.00 at 29.99) & $n=32(38.6)$ \\
\hline Obesity ( $\geq 30.00)$ & $n=14(16.9 \%)$ \\
\hline Groups & \\
\hline With tinnitus & $n=16(19.3 \%)$ \\
\hline Without tinnitus & $n=67(80.7 \%)$ \\
\hline Parameters Tinnitus - THI and VAS & $n=16$ \\
\hline VAS & $4[4]$ \\
\hline THI-Fu & $10[11]$ \\
\hline THI-Em & $7[10]$ \\
\hline THI-Ca & $2[4]$ \\
\hline THI-Total & $18[23]$ \\
\hline
\end{tabular}

Abbreviations: BMI, body mass index); Kg, Kilogram; m, meter; THI, Tinnitus Handicap Inventory; THI-Ca, THI-Catastrophic; THI-Em, THIEmotional; THI-Fu, THI-Functional; THI-Total, total score; VAS (Visual Analogue Scale).

amedian and interquartile range was a significant difference between the Tinnitus and No Tinnitus groups in age $(p<0.001)$ and height $(p<0.045)$. The chi-squared test showed an association between age group and tinnitus $(p<0.028)$; those with tinnitus were in the 49 to 65 years old age group. The other categorical variables (gender, BMI classification, hearing loss, diabetes, hypertension, dizziness, aural fullness) did not show an association, as demonstrated in - Table 2.

Subgroup analyses in the Tinnitus group regarding gender, age group, aural fullness, hearing loss, hypertension, and diabetes were also conducted, but no difference or association was found. Interestingly, there was a moderate correlation between BMI and Tinnitus parameters in BMI and VAS $\left(\mathrm{r}_{\mathrm{s}}=0.604 ; \quad p=0.038\right) ; \quad \mathrm{BMI}$ and THI-Fu $\quad\left(\mathrm{r}_{\mathrm{s}}=0.649\right.$; $p=0.022)$; and BMI and THI-Total $\left(\mathrm{r}_{\mathrm{s}}=0.580 ; p=0.048\right)$ as shown in - Table 3, indicating that, as the BMI increased, so did the impact of tinnitus in the lives of the teachers. A partial correlation controlling the age factor was also conducted for these variables. The correlation between BMI and VAS was moderate $(r=0.630 ; p=0.038)$; however, there was no correlation between BMI and THI ( $p>0.05)$. Interestingly, the Spearman correlation did not show a result between BMI and age $(\mathrm{p}>0.05)$ (-Table 3$)$.

\section{Discussion}

The purpose of the present study was to verify a possible association between tinnitus complaint and BMI in teachers. There was a difference in age but none in BMI, which agrees with other studies that reported a minimized risk of obese people being diagnosed with tinnitus. ${ }^{1,2,7}$ However, a moderate correlation between BMI and Tinnitus parameters was found, indicating that, as the BMI increased, so did the impact of tinnitus in the lives of the teachers. In contrast, another cross-sectional study concluded that tinnitus is correlated with obesity. ${ }^{8}$ A variety of possible causes of tinnitus, as well as differences in the study designs and respective study populations, may have contributed to these contradictory results. ${ }^{7,16,17}$

Tinnitus can be an additional factor for the various teaching-related symptoms - in the present research, the prevalence of tinnitus was of $19.3 \%$. Recent research indicates that a significant number of teachers are concerned with auditory impairment conditions, such as tinnitus, hyperacusis, and hearing loss. Nevertheless, studies focusing on the characteristics and interdependencies of single hearing disorders are rare. ${ }^{18}$ The high prevalence of tinnitus in teachers points to a need for better prevention in their schools and lifestyle to avoid these risk factors. The present study also shows that working as a schoolteacher increases the risk of tinnitus symptoms.

The population of the present study was predominantly female, married, with higher education, teaching in middle school, as in Fillis et al. ${ }^{19}$ The result of accumulating roles produces the so-called double shift, usually combining the professional and domestic activities (as a mother and housewife). This double shift means an intense workload for women, contributing to the development of diseases, 
Table 2 Comparative analyses of continuous and categorical variables of the subgroups with tinnitus and without tinnitus ( $n$;= 83)

\begin{tabular}{|c|c|c|c|c|}
\hline Continuous Variables & & $\begin{array}{l}\text { Tinnitus } \\
(n=16)\end{array}$ & $\begin{array}{l}\text { No Tinnitus } \\
(n=67)\end{array}$ & $\begin{array}{l}\mathrm{P} \\
\text { Mann-Whiney test }\end{array}$ \\
\hline Age (years old) & & $56.5[15.7]^{a}$ & $46[14]$ & $p=0.001^{*}$ \\
\hline Weight $(\mathrm{Kg})$ & & $64.5[30.5]$ & $75[22]$ & $p=0.282$ \\
\hline Height (m) & & $1.58[0.8]$ & $1.65[0.1]$ & $p=0.045^{*}$ \\
\hline BMI & & $27.2[7]$ & $25.6[4.6]$ & $p=0.736$ \\
\hline Categorical Variables & & $\mathrm{N}(\%)$ & $\mathrm{N}(\%)$ & $\begin{array}{l}\mathrm{P} \\
\text { Chi-squared test }\end{array}$ \\
\hline \multirow[t]{2}{*}{ Gender } & Female & $12(75)$ & $41(61.2)$ & \multirow{2}{*}{$\begin{array}{l}p=0.344 \\
x^{2}=0.896\end{array}$} \\
\hline & Male & $4(25)$ & $26(38.8)$ & \\
\hline \multirow[t]{2}{*}{ Age range (years old) } & $27-48$ & $5(25)$ & $40(54.1)$ & \multirow{2}{*}{$\begin{array}{l}p=0.028^{*} \\
X^{2}=4.824\end{array}$} \\
\hline & $49-65$ & $11(75)$ & $27(45.9)$ & \\
\hline \multirow[t]{3}{*}{ BMI (classification) } & Eutrophic & $7(43.7)$ & $30(44.7)$ & \multirow{3}{*}{$\begin{array}{l}p=0.969 \\
x^{2}=0.062\end{array}$} \\
\hline & Overweight & $7(43.7)$ & $25(37.3)$ & \\
\hline & Obesity & $2(12.6)$ & $12(18)$ & \\
\hline \multirow[t]{3}{*}{ Hearing loss } & $\mathrm{NH}$ & $11(68.8)$ & $48(71.6)$ & \multirow{3}{*}{$\begin{array}{l}p=0.280 \\
X^{2}=2.747\end{array}$} \\
\hline & HFLQ & $1(6.2)$ & $8(12)$ & \\
\hline & SNHL & $4(25)$ & $11(16.4)$ & \\
\hline \multirow[t]{2}{*}{ Diabetes } & Yes & $2(12.5)$ & $5(7.5)$ & \multirow{2}{*}{$\begin{array}{l}p=0.515 \\
X^{2}=0.423\end{array}$} \\
\hline & No & $14(87.5)$ & $62(92.5)$ & \\
\hline \multirow[t]{2}{*}{ Hypertension } & Yes & $5(31.2)$ & $15(22.4)$ & \multirow{2}{*}{$\begin{array}{l}p=0.170 \\
X^{2}=1.880\end{array}$} \\
\hline & No & $11(68.8)$ & $5(7.6)$ & \\
\hline \multirow[t]{2}{*}{ Dizziness } & Yes & $8(50)$ & $17(25.4)$ & \multirow{2}{*}{$\begin{array}{l}p=0.070 \\
X^{2}=3.279\end{array}$} \\
\hline & No & $8(50)$ & $50(74.6)$ & \\
\hline \multirow[t]{2}{*}{ Aural Fullness } & Yes & $5(31.2)$ & $10(15)$ & \multirow{2}{*}{$\begin{array}{l}p=0.193 \\
X^{2}=1.698\end{array}$} \\
\hline & No & $11(68.8)$ & $57(85)$ & \\
\hline
\end{tabular}

Abbreviations: BMI, body mass index; HFLQ, normal hearing with high frequency hearing loss; $\mathrm{NH}$, normal hearing; SNHL, sensorineural hearing loss. a median and interquartile range; * statistically significant

Table 3 Spearman correlation between body mass index and tinnitus parameters (VAS and THI) $(n=16)$

\begin{tabular}{|l|l|l|l|l|l|}
\hline & VAS & THI-Fu & THI-Em & THI-Ca & THI-Total \\
\hline & $\mathrm{r}_{s} ; \mathrm{P}^{\mathrm{a}}$ & $\mathrm{r}_{\mathrm{s}} ; \mathrm{P}^{\mathrm{a}}$ & $\mathrm{r}_{\mathrm{s}} ; \mathrm{P}^{\mathrm{a}}$ & $\mathrm{r}_{\mathrm{s}} ; \mathrm{P}^{\mathrm{a}}$ & $\mathrm{r}_{\mathrm{s}} ; \mathrm{P}^{\mathrm{a}}$ \\
\hline BMI & $0.604 ; 0.038^{* *}$ & $0.649 ; 0.022^{* *}$ & $0.445 ; 0.147$ & $0.018 ; 0.955$ & $0.580 ; 0.048^{* *}$ \\
\hline
\end{tabular}

Abbreviations: BMI, body mass index); P, statistical difference; THI, Tinnitus Handicap Inventory; THI-Ca, THI-Catastrophic; THI-Em, THI-Emotional; THI-Fu, THI-Functional; THI-Total, total score; VAS, Visual Analogue Scale.

${ }^{a} r_{s}=$ Spearman correlation value

${ }^{* *}$ statistically significant difference

especially those related to stress, ${ }^{20}$ indicating a need for preventative measures. Another result of the present study was the difference regarding age. The present research agrees with an epidemiological study that assessed 109.783 adults. ${ }^{1}$ The authors found that $\sim 80 \%$ of the cases of tinnitus were diagnosed by the age of 40 years old or older, and that the prevalence increased with age. In addition, a study also demonstrated a higher prevalence of tinnitus in teachers $\geq 48$ years old. ${ }^{1,2,18}$ Overweight is a significant risk factor that contributes to increased morbidity and mortality, and it can also be an additional factor among the various teaching-related symptoms. In the present research, obesity had a prevalence of $16.9 \%$. These results are partially in line with a research that found a higher prevalence in teachers than in the general adult population. ${ }^{9,17}$ However, we cannot derive causality from these present analyses, as we did not intend to run an etiologic study, but rather to descriptively characterize teachers with tinnitus in relation to BMI.

Few studies have related BMI and tinnitus. In the present research, no difference was found between variables, although there was a correlation. A study observed an adjusted odds ratio (OR) for diagnosed tinnitus of 0.91 (95\% CI: 
0.89-0.94) in obese patients (BMI $\geq 30.0 \mathrm{~kg} / \mathrm{m}^{2}$ ), and an adjusted OR of 0.91 (95\%Cl: 0.84-0.97) in underweight patients (BMI $<18.5 \mathrm{~kg} / \mathrm{m}^{2}$ ), when compared with individuals with normal weight. ${ }^{1}$ This may indicate an explanation for the lack of difference in the present study, as there were no underweight participants and only a few obese ones. Probably, a larger sample would provide different results. Another paper, a nationwide, population-based, cross-sectional study, evaluated the relationship between mental health, BMI and tinnitus in 4.628 women. ${ }^{21}$ The data indicated that the overall prevalence of tinnitus was higher in the underweight group, followed by the obesity group; after adjusting for confounding variables including age, women in the underweight group exhibited a higher OR for the presence of tinnitus (OR: 1.54; 95\%CI: 1.14-2.08) than those in the other BMI groups. ${ }^{21}$ Univariate analysis showed that the prevalence of perceived stress was significantly higher in underweight women with tinnitus. It also showed that the prevalence of melancholy and suicidal thoughts was significantly higher in women with tinnitus who were not underweight. The authors suggest that these findings may reflect the relationship between mental health status and BMI. ${ }^{21}$ Based on this assumption, the correlation found between the VAS for tinnitus and THI scores is coherent because both assess the impact of tinnitus on their lives. However, this relationship remains unclear in the literature. Thus, further studies are needed to clarify these findings.

Regarding the instruments, the VAS ${ }^{12}$ was used to verify the sensation of tinnitus, while the $\mathrm{THI}^{13}$ was used to check the level of discomfort it causes in their quality of life - to which end both were effective. These instruments led to the conclusion that there can be differences in tinnitus sensation and discomfort with some BMI and age parameters. These instruments can help direct the treatment and consequently avoid, minimize, or remedy problems arising from tinnitus.

Some limitations should be considered in the present study. For instance, weight and height were self-reported. However, the teachers had a high level of schooling and answered the questions unhesitatingly. Also, body composition was not assessed, which could have given other anthropometric results. ${ }^{22,23}$ Moreover, few obese teachers, mainly with tinnitus, participated in the assessments. Thus, additional studies should be developed to confirm these findings. These observations support tinnitus diagnosing among teachers, especially when approaching the lifestyle and comorbidities patterns of this specific population. Hence, approaching a larger population-based assessment is encouraged. Recent research has verified tinnitus in teachers, especially with a task involving tinnitus in response to exposure to school noise. ${ }^{2,18,24}$ There is still a shortage in the literature of research that verifies the associations between BMI and tinnitus symptoms in teachers.

\section{Conclusion}

In the present study, there was a difference for age, and there was a moderate correlation between tinnitus parameters (VAS, THI-Functional, and THI-Total) and BMI, indicating that, as the BMI increased, so did the impact of tinnitus in the lives of the teachers. Body mass index should be considered a factor in tinnitus assessment and rehabilitation process. These observations may support health professionals when diagnosing tinnitus and when approaching anthropometric factors and other comorbidities in the clinical assessment. Further studies are needed to confirm these findings.

Financial assistance

Fundação Nacional de Desenvolvimento do Ensino (FUNADESP).

\section{Conflict of Interests}

The authors have no conflict of interests to declare.

\section{References}

1 Stohler NA, Reinau D, Jick SS, Bodmer D, Meier CR. A study on the epidemiology of tinnitus in the United Kingdom. Clin Epidemiol 2019;11:855-871

2 Kim HJ, Lee HJ, An SY, et al. Analysis of the prevalence and associated risk factors of tinnitus in adults. PLoS One 2015;10 (05):e0127578

3 Grossan M, Peterson DC. Tinnitus. [Updated 2020 Aug 16]. In: StatPearls [Internet]. Treasure Island (FL): StatPearls Publishing; 2020 Jan-. Available from: https://www.ncbi.nlm.nih.gov/books/ NBK430809/

$4 \mathrm{Wu} \mathrm{V,} \mathrm{Cooke} \mathrm{B,} \mathrm{Eitutis} \mathrm{S,} \mathrm{Simpson} \mathrm{MTW,} \mathrm{Beyea} \mathrm{JA.} \mathrm{Approach} \mathrm{to}$ tinnitus management. Can Fam Physician 2018;64(07):491-495

5 Schultz AR, Neves-Souza RD, Costa VdeS, Meneses-Barriviera CL, Franco PP, Marchiori LLM. Is There a Possible Association between Dietary Habits and Benign Paroxysmal Positional Vertigo in the Elderly? The Importance of Diet and Counseling. Int Arch Otorhinolaryngol 2015;19(04):293-297

6 Gibrin PCD, Melo JJ, Marchiori LLM. Prevalence of tinnitus complaints and probable association with hearing loss, diabetes mellitus and hypertension in elderly. CoDAS 2013;25(02): 176-180

7 Cima RFF, Mazurek B, Haider H, et al. A multidisciplinary European guideline for tinnitus: diagnostics, assessment, and treatment. HNO 2019;67(Suppl 1):10-42

8 Sogebi OA. Characterization of tinnitus in Nigeria. Auris Nasus Larynx 2013;40(04):356-360

9 Rocha SV, Cardoso JP, Santos CA, Munaro HLR, Vasconcelos LRC, Petroski EL. Overweight/obesity in teachers: prevalence and associated factors. Rev Bras Cineantropom Desempenho Hum 2015;17(04):450-459

10 Portney LG. 2020Foundations of Clinical Research: Applications to Evidence-Based Practice. 4th ed. Philadelphia: FA Davis

11 Miller MH. A integração dos achados audiológicos. In: Katz J, editor. Tratado de audiologia clínica. 3 ed. São Paulo: Manole; 1999:268-70

12 Schmidt LP, Teixeira VN, Dall'Igna C, Dallagnol D, Smith MM. Brazilian Portuguese Language version of the "Tinnitus Handicap Inventory": validity and reproducibility. Rev Bras Otorrinolaringol (Engl Ed) 2006;72(06):808-810

13 Doi MY, Tano SS, Schultz AR, Borges R, Marchiori LLM. Effectiveness of acupuncture therapy as treatment for tinnitus: a randomized controlled trial. Rev Bras Otorrinolaringol (Engl Ed) 2016;82 (04):458-465

14 Dias DF, Loch MR, González AD, Andrade SM, Mesas AE. Insufficient free-time physical activity and occupational factors in Brazilian public school teachers. Rev Saude Publica 2017;51:68 
15 CDC. National Center for Chronic Disease Prevention and Health Promotion. Defining Adult Overweight and Obesity . Acess Jun 26, 2020 from: https://www.cdc.gov/obesity/adult/defining. html

16 McCormack A, Edmondson-Jones M, Mellor D, et al. Association of dietary factors with presence and severity of tinnitus in a middleaged UK population. PLoS One 2014;9(12):e114711

17 Conde WL, Oliveira DR, Borges CA, Baraldi LG. Consistency between anthropometric measures in national surveys. Rev Saude Publica 2013;47(01):69-76

18 Meuer SP, Hiller W. The impact of hyperacusis and hearing loss on tinnitus perception in German teachers. Noise Health 2015;17 (77):182-190

19 Fillis MMA, Andrade SM, González AD, Melanda FN, Mesas AE Frequency of self-reported vocal problems and associated occupational factors in primary schoolteachers in Londrina, Paraná. State, Brazil: Cad Saude Publica; 2016;3201 S0102-311 × 2016000100701.
20 Souza CL, Carvalho FM, Araújo TM, Reis EJFB, Lima VMC, Porto LA. Factors associated with vocal fold pathologies in teachers. Rev Saude Publica 2011;45(05):914-921

21 Lee DH, Kim YS, Chae HS, Han K. Nationwide analysis of the relationships between mental health, body mass index and tinnitus in premenopausal female adults in Korea: 2010-2012 KNHANES. Sci Rep 2018;8(01):7028

22 Sebo P, Herrmann FR, Haller DM. Accuracy of anthropometric measurements by general practitioners in overweight and obese patients. BMC Obes 2017;4:23

23 Casadei K, Kie J. Anthropometric Measurement. [Updated 2020 Apr 28]. In: StatPearls [Internet]. Treasure Island (FL): StatPearls Publishing; 2020 Jan-. Available from: https://www.ncbi.nlm. nih.gov/books/NBK537315/

24 Ehlert K. Perceptions of public primary school teachers regarding noise-induced hearing loss in South Africa. S Afr J Commun Disord 2017;64(01):e1-e12 